\title{
PSICOLOGÍA ORGANIZACIONAL CRÍTICA FRENTE A LOS EFECTOS DEL NEOLIBERALISMO CULTURAL. UNA PROBLEMATIZACIÓN DE ASPECTOS PRÁCTICOS Y EPISTEMOLÓGICOS
}

\section{Critical organizational psychology in the face of the cultural neoliberalism effects. A problematization of practical and epistemological aspects}

\section{Félix. A Pineda}

Instituto de Altos Saberes Gerenciales dedicado a la consultoría en Planificación Estratégica, Creación de Capacidades y Desarrollo Organizacional. Doctorando en Filosofía por la Universidad del País Vasco, MBA en Desarrollo Organizacional (Eastern University) y Licenciado en Psicología por el Instituto Tecnológico de Santo Domingo (INTEC). ORCID: 0000-0002-5426-4963, Correo-e: fapineda2017@gmail.com,

Recibido: 21/10/2020 - Aprobado: 4/12/2020

Cómo citar: Pineda, F. A. (2021). Psicología organizacional crítica frente a los efectos del neoliberalismo cultural. Una problematización de aspectos prácticos y epistemológicos. Ciencia y Sociedad, 46(1), 37-55. https://doi.org/10.22206/cys.2021.v46i1. pp37-55

\section{Resumen}

Este artículo analiza la problematización de los aspectos prácticos y epistemológicos relacionados con la configuración de una psicología ocupacional crítica y relevante en el contexto del neoliberalismo cultural. Utilizando un enfoque empírico inductivo y una estrategia de revisión bibliográfica fundamentada en el análisis crítico de enunciados teóricos y autores, sustenta que la psicología organizacional debe reforzar su carácter crítico y pluridisciplinario en el abordaje conceptual y metodológico de la realidad organizacional, sin conformarse con el estatuto de una disciplina profesionalmente más vinculada a los designios ideológicos del gerencialismo. El artículo concluye evaluando los desafíos de la psicología frente a las prácticas gerenciales que, en nombre de la sobreproducción, la eficiencia y el cambio intemperante, están siendo aprehendidas como una virtud en la narrativa empresarial moderna.

Palabras clave: Psicología ocupacional; organización; neoliberalismo; epistemología.

\begin{abstract}
This article analyzes the problematization of the practical and epistemological aspects related to the configuration of a critical and relevant occupational psychology in the context of cultural neoliberalism. Using an empirical inductive approach and a literature review strategy based on the critical analysis of theoretical statements and authors, it is argued that organizational psychology should reinforce its critical and multidisciplinary character in the conceptual and methodological approach to organizational reality, without settling for the status of a discipline professionally linked to the management ideological designs. The article concludes by evaluating the challenges of psychology in the face of managerial practices which, in the name of overproduction, efficiency and intemperate change, are being apprehended as a virtue in the modern business narrative.
\end{abstract}

Keywords: Occupational psychology; organization; neoliberalism; epistemology. 


\section{Introducción}

Este artículo busca problematizar, en primer lugar, la constitución epistemológica de la psicología organizacional, colocando en entredicho el principio dualista de subjeto-objeto, y revisando el abordaje de la realidad organizacional como campo productivo de saberes que, lamentablemente, ha sido configurado como representación vital de la racionalidad neoliberal.

En segundo lugar, se busca articular una discusión enfocada en la aproximación a la realidad organizacional, utilizando los recursos metafóricos de Morgan (Porras Velásquez 2012), reconociendo que tales encuadres (metáforas) constituyen vías interpretativas alejadas del realismo ingenuo. Igualmente, se cuestiona la persistencia del positivismo como criterio de definición del rol de los psicólogos en el ámbito ocupacional, argumentando que la adopción de esta corriente ha contribuido con el empobrecimiento del papel que tienen los psicólogos en el mundo laboral. Y, en tercer lugar, se plantea el efecto pernicioso del neoliberalismo cultural en la configuración de un neosujeto disminuido en su esencia humana, y potenciado como ser instrumentalizado por el capital.

El artículo concluye en que las condiciones de posibilidad de una psicología organizacional robusta, pasan por la superación de las limitaciones epistemológicas y de tipo contextuales que obstaculizan su desarrollo, y la sujetan a los designios de una cultura que prioriza la producción, y relega a un segundo plano al agente humano que produce. Entre estas limitaciones se cuentan prácticas anómalas unas veces, anacrónicas otras tantas, y en la mayoría de los casos, perjudiciales para el desarrollo organizacional como espacio de oportunidad de realización social de los actores involucrados. Más que cuerpo de conocimiento cerrado, se propone que la psicología organizacional crítica está abierta a la discusión prospectiva sobre algunos puntos cruciales, cuyos tratamientos permitan llenar vacíos teóricos que no caben en las disciplinas administrativas modernas.

\section{Precisiones epistemológicas iniciales}

El primer problema que intenta resolver el psicólogo organizacional es el de la constitución de su objeto de estudio que, en este caso, se refiere a la identificación de los supuestos básicos que configuran la existencia de una realidad organizacional en tanto que tal, delimitando la parte de ella que se corresponde con su quehacer profesional investigativo. En dicha tarea, el psicólogo tiene la opción de aproximarse a la comprensión del espacio organizacional desde dos perspectivas filosóficas contrapuestas: la organización pensada como instancia independiente de las representaciones mentales de quien la escudriña, es decir, como "hecho bruto", o como realidad asumida en virtud de la interacción compleja con un sujeto que le confiere sentido, es decir, como "hecho social" (Searle, 1997, p. 20). El segundo problema, no menos complejo que el primero, consiste en determinar las condiciones que posibilitan la estructuración de un cuerpo de conocimientos que permita enforcar, direccionar y abordar apropiadamente la emergencia de nuevos saberes a partir del quehacer profesionalizante o de la práctica investigativa. En el primer caso se hace referencia a la cuestión ontológica, mientras que, en el segundo, se indaga sobre los criterios epistemológicos que hacen factible el conocimiento de la realidad organizacional.

De lo anterior se desprende la urgencia de crear respuestas nuevas a preguntas viejas: ¿es el objeto de la psicología organizacional el estudio de la organización como una totalidad o solo de un fragmento de ella? ¿Se estudia el comportamiento de la organización o el de los individuos en el seno de esta? ¿Bajo cuáles perspectivas teórica se desempeña el rol del psicólogo que presta sus servicios profesionales en una organización? ¿Son las técnicas y las herramientas utilizadas por el psicólogo una construcción heredada del positivismo y del pragmatismo? O mejor, ¿está la psicología de las organizaciones ocupada en los individuos en tanto que individuos, o de las interrelaciones formales e informales que se 


\section{Psicología organizacional crítica frente a los efectos del neoliberalismo cultural. Una problematización de aspectos prácticos y epistemológicos}

generan entre ellos? ¿Son las decisiones y las recomendaciones de los psicólogos resultado de "lo que ellos saben" o de cómo ellos piensan?

Estas interrogantes requieren respuestas bajo la presunción de que las mejores respuestas no son las que satisfacen las demandas lógico-predictivas de una interrogante, sino aquellas que conducen a la problematización de los temas cuestionados. Así, lejos buscar respuestas concluyentes, lo que se busca son nuevas preguntas. En este sentido, vale reivindicar la dimensión filosófica en el quehacer de la psicología laboral: formular preguntas generadoras de nuevas preguntas, en actitud de aprendizaje permanente.

Analizar el estatuto epistemológico de la psicología organizacional obliga atender al odioso problema de la relación entre "subjeto y objeto", el cual, no solo atraviesa la historia de la filosofía occidental, sino que, se normaliza cada vez que se coloca a un profesional (sujeto) de frente a un campo de acción-estudio (objeto). En los postulados de Braunstein, N. A., Pasternac, M. y Frida Saal, G. B. (1982, p. 258), se había alertado ya contra este falso problema. Pero la psicología, ganando una reputación científica cada vez mayor, perdió capacidad reflexiva sobre los presupuestos filosóficos que la constituyen. En clave de Braunstein et al. (1982), "el lugar del sujeto en la ciencia es ocupado por una problemática ideológica que sobre determina, en un cierto momento, la producción de una ruptura epistemológica a partir de la cual ese "sujeto" es desplazado por un nuevo problema” (p. 258). Desde este punto de vista, el sujeto de la psicología organizacional no es un individuo portador de capacidad epistémica para revelar la realidad del entorno laboral. Hablar del sujeto de la psicología organizacional, entonces, es referirse a preguntas (problemáticas) que deben ser respondidas. Siguiendo esta línea de reflexión, el objeto de la psicología organizacional, entonces, es un producto teórico, transitorio, factible de refutación (Braunstein, et al., 1982, p. 259).
En la comunidad de los psicólogos existe consenso en que la producción de verdades científicas irrefutables no es una tarea con la que se pueda establecer un compromiso intelectualmente responsable. Pero a la par, los profesionales de la psicología, y de otros campos de saber, lucen estresado por los criterios de demarcación que definen como científico o no el resultado de su trabajo. Esta preocupación es legítima. Greco (1972) es quien mejor lo ha expresado, al señalar que, "Es la desgracia del psicólogo: nunca está seguro de 'hacer ciencia'. Y si lo está, nunca está seguro de que tal ciencia sea psicología" (p. 19). Se trata de una tensión entre certeza e incertidumbre debido, entre otras razones, a una concepción fetichista del Método Científico (iniciales mayúsculas enfáticas mías), negadora del pluralismo metodológico como opción preferencial en los procesos investigativos de la psicología. Es de rigor plantear que la psicología laboral no tiene un Método, tiene tantos métodos como problemas deben ser resueltos. La tentación de construir discursos explicativos a partir del denominado "Método Científico" como la única vía de acceso al conocimiento, tiene un peso determinante en la generación de "crisis de legitimidad" en los ámbitos de las ciencias sociales y en humanidades, muy a pesar de que, desde el anarquismo epistemológico, se haya demostrado que el camino para llegar a conclusiones válidas y significativas es múltiple y diverso, además de haberse puesto en evidencia que la historia de la ciencia no consiste en el registro de una manera única de proceder.

Llegado a este punto, se hacen necesarias cuatro precisiones:

- Primero, el sujeto de la psicología organizacional se corresponde con una "problemática" que debe ser respondida con los recursos con los que está habilitado el psicólogo, siempre desde una perspectiva crítica, adoptando la posición saussureana de que "el punto de vista crea el objeto". 
- Segundo, el objeto de la psicología organizacional no es un hecho bruto dado, natural, sino la construcción de un producto teórico social y empresarialmente relevante. Este producto teórico, o hecho científico, se conquista, se construye, por medio de una "adecuada vigilancia epistemológica que evite el error de aceptar como científicos, términos que no se forjaron con rigurosidad científica” (Cerón-Martínez 2020).

- Tercero, la pretendida "objetividad científica", herencia del realismo ingenuo, debe dar lugar a la rigurosidad metodológica en el camino hacia la explicación de los problemas identificados, colocando el énfasis en la parte metodológica y no solo en los resultados alcanzados. Una vía factible es la construcción de respuestas intersubjetivas sobre los problemas reales y sentidos de la organización, siempre desde una perspectiva crítica.

- Cuarto, superar la dicotomía subjeto-objeto implica que el psicólogo tiene que analizar y someter a crítica las intencionalidades, motivaciones, puntos de vistas, e intereses que configuran su manera particular de producir e interpretar la realidad organizacional, con lo que, más allá de la concepción binaria, el subjeto deviene, él mismo, en objeto, y de paso, se supera la tentación del individualismo metodológico, que siempre ronda por los senderos de la psicología.

Sin pretender un desplazamiento definitivo del problema "sujeto-objeto", pero validando la propuesta de Braunstein, es preciso acotar el planteamiento de la investigación como un entramado de problemas al que se le busca respuestas generadoras de nuevos problemas. Desde este punto de vista, investigar es problematizar. En el caso de la línea de pensamiento que se defiende en este trabajo, esta problematización está presente: a) en el sujeto que se configura a sí mismo como investigador, b) en el objeto aprehendido como problema, c) en el método como apro- ximación problematizadora y, finalmente, d) en el producto teórico de la investigación, refutado, afirmado, en tanto que una conjetura.

La relación sujeto-objeto, debe ser puesta en suspenso, al menos provisionalmente, para privilegiar la formulación de preguntas: una formulación desde lo conocido hasta lo desconocido. Hacer investigación en psicología ocupacional involucra, entonces, un compromiso con la reflexividad y la objetivación misma del investigador, dando cuenta de las intencionalidades, las motivaciones e interese teóricos desde los cuales se articula el proceso de generación del conocimiento. Se requiere superar, como propone Gutiérrez (2012), la "falsa dicotomía planteada en ciencias sociales entre las perspectivas llamadas objetivistas y las llamadas subjetivistas" (p. 258).

\section{Abordaje metafórico de la realidad organizacional}

La propuesta de este apartado no consiste en afinar una definición sobre lo que son las organizaciones, dado que existe una abundante literatura que facilita una comprensión de esta (Etzioni 1965), (Bernard 1971 citado por Chiavenato 2011), Peiró (1996), Porter, Lawler y Hackman (1975), Cruz (1982), Schein (1991), Rodríguez-Fernández (1998), Dávila (2001). De Rivera Porras, Carrillo Sierra, Forgiony Santos, Nuván Hurtado y Rozo Sánchez (2018), puede deducirse que la organización consiste, en términos generales, en un microambiente formados por individuos que interactúan unos con otros, situados en tiempo y espacio delimitados, generando una cultura que, a su vez, incidirá en la forma misma de la interacción entre los distintos atores que la conforman. Desde la perspectiva de este trabajo, la organización es un espacio de realización social en el que interactúan personas, procesos, sistemas y actantes, en la generación de prácticas y saberes que se conjugan para la realización de proyectos en los que cuentan, no solo los resultados, sino también los medios, no solo la acción, si también el enfoque de la acción. 


\section{Psicología organizacional crítica frente a los efectos del neoliberalismo cultural. Una problematización de aspectos prácticos y epistemológicos}

La cuestión privilegiada aquí es la del abordaje de la realidad organizacional. Porras Velásquez (2012) plantea el recurso metafórico como forma de comprensión de la realidad de una organización, replicando las ocho conocidas metáforas de Morgan.

La primera imagen es la de una máquina burocrática, en la que se plantea que una entidad puede ser ordenada en su diseño y en su funcionamiento, generando patrones fijos de comportamientos en los que tiene cabida el ideal burocrático de organización. Este modelo funciona como una pieza de ingeniería y apunta a la organización como si se tratara de una máquina. La burocracia, en su valoración positiva (Bozeman, 2015), implica un alto nivel de profesionalismo, junto con un alto nivel de autonomía burocrática. No obstante, desde una posición anarquista, se va a criticar el hecho de que se haya vuelto imposible pensar la existencia de nuestra cultura sin la presencia de la burocracia (Graeber, 2015, p. 174). A partir de los postulados críticos de Graeber, pareciera que la "Ley de hierro del liberalismo" aplica igual al funcionamiento de la burocracia, de tal manera que, cualquier intento por reducir la cantidad de burocracia siempre terminará en un incremento de esta. La burocracia hoy, lejos de ser un medio, alcanza niveles de fines.

La segunda imagen es la de la organización vista como un organismo. Contrario a una visión mecánica de esta como máquina, se formula la idea de la organización como una entidad capaz de adaptarse a los entornos para asegurar su existencia. Desde la biología se toma prestado un lenguaje que permite aplicar a las organizaciones los mismos términos utilizados para describir el desarrollo vital de un organismo: nacen, crecen, se desarrollan y, en clave darwiniana, se adaptan a sus respectivos entornos, compiten entre sí por los recursos, y finalmente mueren.

Dittus y Vásquez (2016) han realizado un trabajo en el que sostienen que, para comprender los mecanismos constituyentes de las organizaciones, se deben estudiar los procesos narrativos que distinguen a la organización como unidad, tomando en consideración el concepto de autopoiesis desarrollado por Maturana (Maturana y Varela, 1994, p. 71). La recepción que ha tenido el concepto de autopoiesis en las ciencias sociales es bastante conocida. Se refiere al ser vivo como modelo de autogeneración de capacidades interpretativas, rasgo autónomo que se aplica para comprender el funcionamiento de los sistemas sociales.

La tercera imagen hace la comparación de una organización con un cerebro. La idea es que, así como un cerebro puede aprender, las organizaciones también, bajo circunstancias equiparables, siendo autocríticas, innovadoras y con capacidad autónoma para la resolución de problemas. Desde esta visión, una organización inteligente es aquella que ha sido diseñada con sistemas especializados que se interconectan entre sí, en una dinámica cubierta por los recursos de la tecnología de la información y del dataismo, por ejemplo. Una organización de aprendizaje es, entonces, aquella capaz de incorporar lecciones aprendidas a su dinámica cotidiana, y sistematizar buenas prácticas que resulten replicables para su propio crecimiento.

La cuarta metáfora se mueve hacia la cultura. Se propone que la realidad organizacional ha de ser comprendida como un sistema cultural, en tanto que conjunto de valores, ideas, normas, principios, rituales, creencias y capacidades compartidas entre sus integrantes. Comprender a la organización es comprender su sistema de significados reflejado en pensamiento, decisiones y acciones.

La quinta imagen se refiere a la organización como sistema político. Aquíse destacan los conflictos de intereses entre los involucrados y, sobre todo, las maneras en que se configuran las redes de poderes y micropoderes en el espacio organizacional. Adquiere particular importancia el organigrama y los flujos verticales de toma de decisiones. Las relaciones entre los distintos 
equipos e individuos son analizadas como relaciones asimétricas de poder generadoras de distorsiones que se manifiestan en la forma de un "equilibrio inestable". Para los partidarios de esta imagen, las ideas de los integrantes de una organización están limitadas por el contorno ideológico de la misma, de manera que el grado de integración será relativo al grado de identificación del individuo con tales contornos. Las organizaciones buscan la manera de lograr un orden y dirección entre gente con diversidades potenciales y en un continuo conflicto de intereses (Rocha Blanco, Cobo Ortega, \& Vanti, 2013).

La sexta imagen, mal llamada "prisión psicológica", implica un entendimiento de lo organizacional como espacio en el que los colaboradores aparecen atrapados por sus propios pensamientos, ideas y creencias que se originan en la parte inconsciente de la mente. Comprender una organización es entender tanto las motivaciones internas de cada uno de sus involucrados como los aspectos ideológicos y psicodinámicos que condicionan su desempeño (Morgan, 1998 citado por Porras Velásquez, 2012).

La séptima imagen es la de la organización como flujo de cambio y transformación. Este abordaje sostiene que la vida social de una organización está configurada por una lógica de cambio continuo. Esta metáfora cobra fuerza inusitada con la principalía que se otorga a la innovación y a lo disruptivo. Se destaca, como antítesis a esta imagen, que tanto lo disruptivo, como la tesis del cambio permanente, lejos de ser asumidos como presupuesto estructurante de la empresa moderna, exige un replanteo crítico, dado que la observación empírica confirma que muy pocas organizaciones explican su progreso como función de la innovación disruptiva constante, ni del cambio intemperante. ¿¿Será esta una línea de investigación que demanda ser abierta, aun en contra de la creencia popular de "innovar o morir? ¿Será que la idea de que "lo único permanente es el cambio" amerita ser sometida a crítica, no por su grado de certeza, sino por su uso descontextualizado?
La última metáfora se refiere a la organización como instrumento de dominación. Esta imagen muestra el espacio organizacional como un escenario de dominio en el que se utiliza y explota a los empleados para conseguir los fines organizacionales. Al igual que en la metáfora "política" aquí se genera una lucha en la que personas, o grupos de personas, intentan imponer sus criterios sobre el resto o sobre una parte del personal.

En cada una de las metáforas revisadas, la realidad organizacional se define como un fenómeno complejo diseñado para alcanzar unos fines estratégicos (horizonte de posibilidad) mediante acciones y decisiones concretas (marco de acción). En cualquier caso, el estudio de esta realidad se enmarca en tres ámbitos: a) diseño, b) descripción y c) explicación. Desde este estudio, se propugna que estos tres ámbitos no son suficientes para perfilar el trabajo del psicólogo organizacional, porque excluyen el campo de los significados. Las organizaciones son sistemas de narraciones, y en la medida en que sus miembros construyen narraciones, en esa misma medida configuran el discurso constitutivo que va a identificar la cultura organizacional. Dittus y Vásquez (2016) asumen el "giro narrativo" asociado al estudio del management aceptando que las organizaciones son microcosmos donde se producen y circulan múltiples narraciones, desde las huelgas hasta las maquinaciones para acceder a mejores salarios.

La realidad organizacional no es algo "dado", como se pensaría adoptando una postura realista ingenua, sino una realidad socioconstruida, en función de formas determinadas de interpretar la realidad. Desde este enfoque, lo importante no es la realidad en sí (noúmeno kantiano), sino la percepción colectiva de las personas sobre ella (fenómeno). Son esas percepciones, interpretaciones, discursos, enunciados sobre las organizaciones, las que acaban configurando la propia realidad a la que hace referencia Porras Velásquez (2012). Entendido de esta forma, los hechos organizacionales son hechos cargados de sentido, pero lo son en la medida en que los actores 


\section{Psicología organizacional crítica frente a los efectos del neoliberalismo cultural. Una problematización}

de aspectos prácticos y epistemológicos

organizacionales imprimen dicho sentido y no de otra manera.

\section{Problematización del rol del psicólogo organi- zacional}

Pulido-Martínez y Jaraba (2017) han tratado de orientar la constitución del quehacer del psicólogo a partir de tres interrogantes: ¿qué es un psicólogo?, ¿qué hace el psicólogo?, ¿qué se hace con lo que hace el psicólogo? El abanico de respuestas es amplio y diverso, pero la observación empírica permite tamizar algunos elementos prioritarios: a) respuestas de orden académico, enfocadas en presupuestos teóricos, modelos, enfoques y líneas investigativas heterogéneas, b) respuestas de orden profesionalizante, enmarcadas en prácticas laborales, aplicaciones concretas, diseños, etc., y c) respuestas de orden crítico, proveniente del cuestionamiento a los marcos teóricos tradicionales y de la práctica que le sirve de legitimación.

La opción "c" resulta relevante porque con ella se ponen en la mesa nuevas propuestas teóricas provenientes de mundos distintos desconocidos para los pioneros de la psicología tal como se conoce hoy. Pero, además, esta opción resulta ser la más productiva porque abre nuevas fisuras ontológicas, epistemológicas y metodológicas sin las cuales no se podría hablar de psicología en las próximas décadas, con la puesta en común de la robótica, la inteligencia artificial, sujetos híbridos, fenómenos disruptivos adversos como la Covid-19, actantes, Antropoceno, entre otros. En cualquier caso, las tres interrogantes de Pulido-Martínez y Jaraba son bienvenidas porque van a servir para problematizar el quehacer del psicólogo en el plano de la organización.

Si la realidad organizacional se constituye como realidad discursiva, es preciso prestar atención a la forma en que los roles del psicólogo organizacional alcanzaron el nivel de aceptación del que disfrutan en la actualidad. Entre los discursos vigentes, se asigna al psicólogo organizacional la capacidad de decidir acertadamente quién es la persona ideal para ocupar un puesto de trabajo. A este rol se agregan otras funciones tales como la de investigar la disponibilidad de recursos humanos en el mercado laboral, la de realizar análisis de cargos y las tareas que deben cumplir los colaboradores para alcanzar las metas, así como realizar tareas de reclutamiento y selección. Orozco Rincón et al. (2013) recogen otros roles ya clásicos: asegurar que el personal que ingrese a la organización se adapte y progrese en ella mediante el desarrollo de planes de carrera, evaluar el clima, medir el desempeño y motivar al personal. En la lista aparecen algunas funciones contradictorias como, por ejemplo, trabajar para que los despidos de las personas sean satisfactorios. Un peldaño más elevado en el perfil mira al psicólogo trabajando para el desarrollo de la cultura, afrontando los conflictos y las contradicciones internas. Y en la parte más elevada, aparece la de contribuir a una visión sistémica y holística del comportamiento humano en la organización, y de esta dentro del entorno social, legal y cultural.

En el caso de Latinoamérica, estos roles tienen el beneplácito de los centros universitarios que no reflexionan críticamente las prácticas docentes, validando saberes considerados como neutrales y universales, pero que no son más que un producto de la colonización del conocimiento hegemónico (Vera Ruiz, Llanco Gonzales \& Guevara Rojas, 2019). En ese sentido, Mandiola (2018) va a destacar que la pretendida universalidad y neutralidad de los enunciados gerenciales, lejos de una contribución, constituye una restricción al desarrollo de una teoría del management, dado que no da cuenta del marco de los intereses particulares que prima en los autores. En ese mismo orden de pensamiento, Polo Blanco (2016) abraza el término de "decolonización epistémica" como forma de liberación de los conocimientos enlatados proveniente de latitudes con un contexto bastante diferenciado. 


\section{Rol del psicólogo organizacional en perspectivas}

Desde la perspectiva de una psicología crítica, el rol del psicólogo en el entorno laboral implica, como señala Andrade (2013), abrir a otras posibilidades los discursos existentes, y empezar a propender hacia la creación de nuevas narrativas. En estas nuevas propuestas, el perfil del psicólogo organizacional incluye problematizar las tensiones que jalonan la subjetividad de los trabajadores. De no ser así, un psicólogo laboral sería, en el mejor de los casos, un técnico de talento humano especializado en trámites que hacen viables los dispositivos burocráticos que determinan los pensamientos, las decisiones y las acciones en una organización.

El diseño del perfil del psicólogo organizacional pasa por el cedazo de la tradición crítica, despojándolo de las "verdades psicologizadas" que legitiman una lógica en la que la producción se superpone al productor. ¿Pueden los psicólogos del trabajo continuar creando las condiciones para la "empresarización de la vida? La respuesta de Wittke (2005) es, a todas luces, negativa. Este autor se resiste a que "el éxito sea concebido como un parámetro de realización dentro del plano organizacional" (p. 155). En efecto, la acreditación de los recursos de calidad total, cero errores, equipos de alto desempeño, efectividad organizacional, enfoque en resultados, innovar o morir, renovación radical, emprendimiento, modelo de producción lean, máximo rendimiento, entre otros, no son más que constructos configuradores del sujeto neoliberal de la sobreproducción, con el bautizo normalizador, en el peor de los casos, de los psicólogos laborales, aun cuando se sabe que cada uno de los temas citados son portadores de valor, siempre que sean expresados como una función de enriquecimiento de la persona trabajadora, y no "a pesar del" empobrecimiento de su dignidad.

No se pretende que un cambio radical en el sistema trabajo capital sea viable, por lo menos no se percibe que lo sea en el mediano plazo, dada la profundidad con la que la cultura neoliberal ha moldeado las estructuras sociales y la subjetividad misma del trabajador. Sin embargo, la adopción de una postura crítica puede servir de palanca de cambio en los enfoques estratégico de los temas en cuestión, asegurando giros paradigmáticos, en los cuales los psicólogos tienen mucho que aportar.

Posicionar los roles del psicólogo organizacional desde una propuesta crítica obliga a superar distorsiones ideológicas que asumen el valor personal, la autoestima, la realización humana, por citar algunos ejemplos, en función de un rendimiento marcado por la excelencia, en el que ser competitivo deja de ser sinónimo de superación humana para convertirse en lucha despiadada por el logro de unos objetivos propuestos desde un lugar diferente al propio. Una perspectiva crítica, más que adopción de patrones ideológicos determinados, constituye una manera rigurosa de someter a examen lo que durante años se ha presentado como obvio en el mundo de las organizaciones. Un ejemplo clásico se encuentra en el constructo de "identidad" entendido como "ser uno con la organización", en el que los uniformes, los símbolos, las rutinas, los colores institucionales y el apego a los valores cobran sentido, como un marco de "valores y normas que son compartidos por los miembros de la organización" (Bravo Gil, Matute Vallejo y Pina Pérez, 2016).

Llegado a este punto, se validan las aserciones de Pulido-Martínez y Sato (2013) al considerar que una "contra psicología" enfocada en el trabajo y en las condiciones en que este se ejecuta, permite tomar distancia del enfoque gerencialista que concibe a los trabajadores como recursos destinados a incrementar utilidades, y se abre la oportunidad de construir una visión del trabajo como horizonte de posibilidad para la transformación del mundo social, sin la instrumentalización de las personas. El espacio del profesional en psicología organizacional es, entonces, el desarrollo de la organización entendida como hecho plural complejo, que va más allá de la exaltación de las utilidades. 
En esta nueva manera de concebir el rol, se conjugan, como ya fue dicho, personas, proceso, sistemas y actantes. El psicólogo no está llamado a estudiar a cada uno de estos elementos por separados, sino la "realidad" que se genera como resultado de las interacciones entre unos y otros. Estudia el impacto que tiene la acción humana en los procesos, sin dejar de analizar el efecto inverso. Esta mirada exige repensar la base epistemológica sobre las que se edifica el oficio del psicólogo organizacional, tomando en consideración los nuevos escenarios laborales, entre los que se cuentan: primero la virtualización del trabajo (ahora impulsada por la situación de la Covid-19), segundo la irrupción de la inteligencia artificial que transforma al robot, no en actor, pero sí en actante, y tercero, la cuestión de los individuos empresarios de ellos mismos en la modalidad del emprendedurismo.

En un plano menos superficial, el psicólogo organizacional carga la responsabilidad de dar cuenta de la reflexión que la organización hace sobre ella misma (nivel reflexivo del rol), de la acción de la organización sobre ella misma (nivel operativo del rol) y, por último, dar cuenta del horizonte de posibilidades del capital intelectual y humano constituido en capital organizacional (nivel estratégico del rol). Es indiscutible entonces, como sugieren Álvarez Silva, Estrella Marín y Rosas Baldeón (2018), que el rol del psicólogo en la organización no se reduce a la ejecución de procesos específicos relacionados con el talento humano. Por lo contrario, es un rol que contribuye a la transformación de la organización en un mejor espacio de realización social de los actores involucrados, en la misma medida en que contribuye al logro de los objetivos institucionales en tres niveles: productos, resultados e impactos.

\section{Psicología organizacional crítica contra los efectos perniciosos del neoliberalismo cultural}

\section{Neoliberalismo cultural}

El campo de acción de la psicología organizacional no es ajeno a las turbulencias generadas por la cultura neoliberal. En este sentido, existe un nexo entre las organizaciones y la producción cultural implicadas en la etapa actual del neoliberalismo, que debe ser atendido con prudencia. Aunque neoliberalismo y cultura son, conceptualmente, dos campos de investigación disímiles, Belaustegi (2017) ha emprendido la tarea de identificar la cultura neoliberal como foco de trabajo productivo desde una postura que permite comprender y reaccionar sobre temas que se presentan como inevitables. Belaustegi articula su análisis, en primer lugar, a partir de la cuestión de la primacía del mercado como punto neurálgico. En segundo lugar, hace referencia al trasfondo discursivo de Foucault y pone su énfasis en una gubernamentalidad neoliberal basada en la racionalidad competitiva conformadora/ gobernadora de las subjetividades, constituyendo la génesis de un nuevo sujeto liberal. Para los fines que interesan a este estudio, se enfatizará esta segunda vía de análisis.

El neoliberalismo tiene una virtud esencial: la competencia. También tiene un modelo de racionalidad: la empresa. Siendo de esta manera, Harvey observa que los valores de la individualidad (libertad personal y libre mercado) sustituyen a los de la comunidad como creadores de sociedad (Harvey, 2007, p. 75). Esta narrativa es lo suficientemente coherente para llenar los intersticios de la vida humana, y para lograrlo, nada más efectivo que ocupar el campo de la cultura como universo de creación de sentido.

Desde la psicología social, se ha realizado un diagnóstico de los efectos del neoliberalismo, concentrando la atención en las consecuencias psicosociales negativas en el mundo del trabajo. Aunque las consecuencias son desastrosas y contra humanas, el capitalismo actual ha creado un discurso que legitima el estado actual como el mejor de los estados posibles. La conclusión de este proceso es preocupante, pero con gran aceptación: "El neoliberalismo ha colonizados las subjetividades, dejando de ser algo externos a nosotros, se ha instalado en nosotros mismos, 
como creyentes de una nueva y única fe (Ovejero Bernal, 2014, p. 34).

Belautegui insistirá en que el neoliberalismo, entendidos en la visión de Foucault, es una forma de gobierno (gestión) y conformación de subjetividades, pero, sobre todo, y esto es lo interesante, desde ellas mismas, y no solamente como receptoras de la acción de los políticos, gestores o gobernantes. Surge así el sujeto neoliberal en la forma de individuo-empresa, que se asume a sí mismo como emprendedor en un entorno competitivo, y en una lógica que Laval y Dardot (2013) definen como "dispositivo de rendimiento" (p. 326). En esta tesitura, el neomanagement, el gerencialismo moderno, se interpreta como una forma de mercantilización del trabajo, mediante el alineamiento de emociones, pasiones, deseos, etc., con los fines institucionales. Como lo describen Laval y Dardot (2013) "La gran innovación de la tecnología neoliberal consiste en vincular directamente, la manera en que un hombre es gobernado con la manera en que se gobierna a sí mismo" (p. 337). Esta afirmación aparece impregnada en la dinámica cotidiana de la gente y cobra sentido en lo que, desde este análisis, se denomina cultura neoliberal o neoliberalismo cultural.

La empresarización del subjeto neoliberal funciona. Para los defensores de esta lógica, el proceso de humanización del hombre ha concluido, dando lugar al de la empresarización. El proyecto neoliberal se presenta como totalizador precisamente por su dominio sobre la esfera cultural, en la que introduce una concepción fatalista que sugiere que el orden vigente carece de alternativa. Lo "anormal" sería, en claves del culturalismo neoliberal, la negación del orden "normal". En este encuadre se justifica la negación de todo movimiento que ponga en juicio la "normalidad" neoliberal.

Concebir el neoliberalismo como una cultura es pertinente, justo cuando se sabe que este, además de su impacto en la cotidianeidad, atraviesa también la vida espiritual. Se ha acuñado el término de "neoliberalización espiritual" para describir el proceso de naturalización social y cultural de la idea neoliberal que promueve formas de subjetivación que suponen la mercantilización del espíritu (Contreras, 2015 citado por Belaustegi 2017). Precisamente a esta cuestión se refieren los Critical Management Studies (estudios críticos del gerenciamiento), cuando sostienen que lo que hoy se conoce como cultura organizacional, no es otra cosa que la apropiación por parte del trabajador, de los aspectos simbólicos que se entretejen al interior de una organización, y mediante los cuales se ejerce el control cultural entendido como gestión de los símbolos. En este formalismo cultural entran la visión, la misión, los valores y la promesa de valor, en tanto que forjadores del horizonte estratégico empresarial, pero también caben los rituales diarios, los colores institucionales, los uniformes, el cuidado de la marca, etc., que confieren integración y homogeneización a los procesos formativo del individuo corporativizado.

Hasta aquí la argumentación acerca del carácter cultural del neoliberalismo resulta incontrovertible, tanto, que algunas voces, Colussi (2018) entre ellas, prefieren una mirada crítica en la que el neoliberalismo deja de ser una fórmula económica para devenir en un programa civilizatorio. Esa línea de razonamiento es abrazada por Hernández Colorado (2017), quien se refiere al neoliberalismo como una visión del mundo, de lo humano y del orden social bastante específico. En este orden, la receta neoliberal es clara, aparentemente razonable y atractiva: que la gente decida, que los consumidores decidan, que nadie se meta en su vida (Escalante, 2015, citado por Hernández Colorado, 2017). De ahí, nace una nueva concepción de la sociedad, intensamente individualista, privatista, insolidaria, más desigual, conforme y satisfecha con esa desigualdad. Oro Tapia (2018) lo cree igual, cuando señala que se trata de una concepción del mundo y del ser humano, de una cierta manera de vivir la vida, en fin, de una cultura. El neoliberalismo, como toda 


\section{Psicología organizacional crítica frente a los efectos del neoliberalismo cultural. Una problematización de aspectos prácticos y epistemológicos}

fórmula cultural exitosa, opera en la vida cotidiana de manera eficaz e inconsciente.

\section{Efectos perniciosos del neoliberalismo cultural}

Entre las concepciones desplegadas por el neoliberalismo, aquí se identifican aquellas directamente vinculadas con la composición de una cultura que no es ajena al psicólogo organizacional. La primera apunta hacia la exaltación del individuo, la segunda se relaciona con la libertad y la tercera con la conformación de un individuo neoliberal. El impacto de este "triángulo pernicioso" aparentemente inocente, obliga a un posicionamiento ético radical en el que no cabe ninguna forma de neutralidad.

Primero se construye, como piedra filosofal de la cultura neoliberal, una visión superficialmente propositiva, pero profundamente contradictoria, del individuo. Friedrich Hayek en su libro "Derecho, legislación y libertad", apunta hacia la inexistencia de la sociedad, argumentando que lo que suele llamarse "sociedad" no es sino un conjunto de individuos aislados, sin ninguna relación entre sí, más allá de los intercambios que estos realizan en el mercado. En efecto, la no existencia de la sociedad implica la existencia de individuos colocados frente a frente, en un escenario delimitado por el mercado, en el que no hay cabida para la idea de justicia social (Martínez Rodríguez, 2013, citado por Pérez Serrano, 2014), ni de bienestar social, sino únicamente la propiedad privada (Alvarado Peterson, 2019). Se hace evidente, la primera gran perversión de la cultura neoliberal: entronizar la figura del individuo, cuando lo que real y efectivamente se hace es destruirlo para exaltar lo "individual" como categoría de análisis.

La segunda idea capital se encuentra en el término libertad. Si la verdad primera desemboca en la exaltación de la figura de lo individual, la verdad segunda expande el sentido de la libertad. Ambos se conjugan en un encuentro armonioso denominado "libertad individual". La prédica común es que el hombre es libre de elegir, entre todas las opciones disponibles, aquellas que sean de su preferencia. Sin embargo, esta concepción plantea un problema no resuelto denominado "idea tramposa" de Lacan sobre la "elección", en la cual no ocurre ninguna elección, porque la misma ya estaba tomada en las opciones a las que se expuso al sujeto, y por las determinaciones sociales, económicas, políticas y culturales que cubren los aspectos relativos a una decisión individual (Battista y Pollo, 2017). En el entorno neoliberal, el individuo está libremente llamado a elegir aquello que se le es permitido escoger. ¿Cuáles posibilidades de elección tienen los 26 millones de latinoamericanos que viven en la indigencia? En síntesis, desde la lógica del neoliberalismo cultural, los pobres son pobres porque quieren. Es decir, la pobreza se define como el estado aislado de algunas personas, de una característica individual, desvinculada de todo condicionamiento político, social o económico (Peña y Toledo, 2017).

Chul Han (2019) recuerda que "sujeto" literalmente significa "estar sometido" (p. 11), y agrega que el sujeto del rendimiento, que se pretende libre, es en realidad un esclavo. Es un esclavo absoluto, en la medida en que, sin amo alguno, se explota a sí mismo de forma voluntaria (Chul Han, 2019, p. 12). En el plano de la organización, la libertad fue puesta en suspenso, y en su lugar, se afirman los términos de la contratación que, satíricamente se denomina "acuerdo laboral" cuando fueron elaborados por una sola de las partes involucradas. Paradójicamente, cuando los liberales hablan de libertad individual, de lo que hablan es de libertad del capital y esclavitud del individuo. De manera similar, cuando se habla de desarrollo del personal, se discursea, en realidad, de la capacidad de un colaborador de aportar al logro de las metas institucionales.

La tercera idea fundante de la perversión del neoliberalismo cultural es la constitución de un neosujeto liberal, matizado por lo que Chul Han (2019) 
denomina "optimización de la psique como fuerza productiva” (p. 42). La promesa del incremento ilimitado de la capacidad productiva del ser humano tiene mucho de distopía y poco de utopía, pero en ella se consuma el nuevo hombre-mujer neoliberal. La psicopolítica sienta las bases para un amplio programa de inducción con capítulos claves en la motivación y superación personal, la gerencia de sí mismo, coaching empresarial, inteligencia emocional, entrenamiento y la adopción de la industria de la felicidad, con el propósito de crear el nuevo hombre (neosujeto liberal) unidimensional, centrado en la ideología de la optimización.

De esta manera, quienes encuentran reparos en el dominio absoluto del capital sobre la vida, deben ser reeducados en la normalidad de la eficiencia y de la competencia darwiniana, en la que los menos aptos son descartados para dar lugar a los vencedores. Afortunadamente, la vida humana encuentra las grietas del sistema, y se abre la oportunidad a una crítica a lo que, otra vez, el filósofo coreano Chul Han (2019) va a denominar "el evangelio del rendimiento y de la optimización sin límite" (p. 49). Si bien es cierto que Chul Han no puede ser tomado como una receta, lo cierto es que permite hacer una descripción bastante confiable del estado de situación actual.

Si existe un espacio formal en el que el neoliberalismo cultural ha entrado por la puerta ancha con su programa constitutivo del neosujeto liberal, este lugar es la organización. Lo es, en el sentido en que la empresa ha sido tomada como modelo de racionalidad neoliberal. Los psicólogos viven esta experiencia en un doble sentido: primero como actores centrados en el análisis del comportamiento de los trabajadores, y segundo, como actores que se miran a sí mismos como trabajadores. Esta manera de "mirar hacia adentro estando dentro" cobra una dimensión favorable para la reflexividad porque, el psicólogo que trabaja con empleados es también un empleado.
De Armas Pedraza, Venegas Ahumada, Salas y Aguilar-Bustamante (2019) han realizado un estudio en el que dan cuentas de cómo, en el caso de Chile, la instauración del neoliberalismo ha derivado en efectos letales para el ejercicio profesional de la psicología, generando la proliferación del trabajo no decente (precariedad laboral/ flexibilidad laboral), que se ha llegado a ubicar hasta en un desagradable $64.5 \%$ de los psicólogos que ejercen la profesión. Esta situación implica un marcado proceso de desprofesionalización. A la precarización del trabajo sigue, como consecuencia funesta, la des-colectivización, derivada de una concepción utilitarista de los derechos individuales. De esta manera, los gremios pierden su capital social, y su sentido de cohesión pasa a girar alrededor de la realización de actividades de integración empresarial.

De lo que se trata, cuando se hace referencia a los efectos perversos del neoliberalismo cultural es, en primer lugar, a la difusión de la idea de que para el orden establecido no existen alternativas que sean viables. En efecto, al tomar por asalto los estamentos de la vida política, social, cultural y personal, el proyecto neoliberal se vuelve omnipresente. Paradójicamente, este "estar" en todos los ámbitos de la vida, incluido el espiritual, es lo que hace posible su invisibilidad. El neoliberalismo se vuelve cultura dominante, y al hacerlo, se torna invisible. Es por esa razón que, desde el sentido común no riguroso, el neoliberalismo, culpable de grandes calamidades, queda exento de culpas.

\section{Condiciones de posibilidad de una psicología organizacional crítica}

Las condiciones de posibilidad de una psicología organizacional crítica aparecen vinculadas, no solo a la comprensión y solución de los problemas derivados del neoliberalismo cultural, sino también, a una correcta vigilancia epistemológica frente a corrientes y tendencias psicológicas que buscan posicionar una manera específica de hacer psicología, privilegiando 


\section{Psicología organizacional crítica frente a los efectos del neoliberalismo cultural. Una problematización de aspectos prácticos y epistemológicos}

la acomodación de la disciplina a las demandas imperantes en el entorno. La primera cuestión importante aparece con la denominada psicología organizacional positiva, la cual se ajusta perfectamente al escenario del sujeto liberal llamado a tener éxito. Es bueno recordar que, en el entorno laboral posmoderno (pero con las mismas premisas de la modernidad), el sujeto que fracasa es culpable de su fracaso, y como es de esperarse, la psicología debe ayudar a redimir, con la narrativa terapéutica vigente, al neosujeto, inyectándole altas dosis de motivación, y potenciando sus facultades productivas ilimitadas. En esta parte, tanto la psicología positiva (Cuervo-Carabel, Meneghel, Orviz Marínez y Arce-García, 2020), como la denominada inteligencia emocional (Manrique Solana, 2015), cumplen su cometido. Se plantea entonces, que una psicología organizacional de carácter crítico deviene en una contra psicología frente a la copiosa producción de literatura de superación personal, coaching organizacional, inteligencia emocional e industria de la felicidad.

Las condiciones de posibilidad de esta psicología involucran un conjunto de propuestas que, aunque disperso en su planteamiento, está entretejido en un marco conceptual y metodológico compacto.

Apertura de nuevas líneas de investigación en los diversos campos de acción de la psicología organizacional tales como: redes de comunicación internas, decisiones intersubjetivas, poder horizontal compartido, liderazgo de soporte, cooperación, conflicto, cultura, estructuras no jerárquicas, innovación social, modelos organizacionales autosostenibles, equipos autodirigidos, cambio e inteligencia artificial, entre otros. En cada caso, se busca delimitar qué es y qué no es psicología organizacional (del Cerro, 2013).

A. Superar el enfoque psicológico centrado en el individuo indeterminado, sometido a análisis fuera de su contexto, y colocar en su lugar a la "persona”, al sujeto pensante y sintiente (Valverde Brenes, 2014).
B. Los psicólogos organizacionales deben ir al encuentro con las realidades de los hombres y mujeres del mundo laborar, estableciendo compromisos sustantivos de contribución al desarrollo de su potencial humano, en los ámbitos operativos, gerenciales y de liderazgo.

C. La industria de la autoayuda como técnica de superación personal de los trabajadores, la psicología positiva aplicada en el plano organizacional (Coyne y Tannen, 2010), la falacia de la ecuación de la felicidad (Pérez-Álvarez, 2012), así como la tiranía de la actitud positiva (Held, 2002, citado por Pérez-Álvarez, 2012), constituyen planteamientos populares que requieren de una mirada crítica no conformista, por carecer de rigor científico (Pérez-Álvarez, 2012).

D. Pasar del paradigma del colaborador como "principal activo de la organización" (carácter instrumental) al del colaborador "constructor de activos", (carácter de actor-agente de transformación) bajo la premisa de que ningún ser humano debe ser reducido a condición de "medio" (Palomino, 2015).

E. Una psicología organizacional crítica preconiza el abandono necesario del individualismo metodológico que establece que todos los problemas pueden ser tratados desde una perspectiva individual, es decir, atendiendo al individuo como origen y destino de cualquier proceso, borrando los condicionamientos sociales, económicos, culturales y de tipo históricos que hacen de un trabajador un "ser situado".

F. El psicólogo organizacional está llamado a realizar una contribución estratégica basado en el principio de simetría, en la que el colaborador contribuye al desarrollo de la organización en la misma medida en que la organización contribuye al desarrollo del colaborador. Es decir, la contribución del colaborador no será la correcta 
si no lleva implícita, el aspecto de realización humana y profesional derivado de su propia contribución.

G. Los psicólogos de la organización deben mantenerse en estado de alerta epistemológica permanente frente a lo que Jorge Alemán denomina "invención de la subjetividad" por parte del neoliberalismo (Zubillaga, 2018). En la tesitura de Alemán, aunque el neoliberalismo puede producir la subjetividad, no puede apropiarse por completo del sujeto, porque de lo contrario, el crimen sería perfecto (Giuliano, 2018), abriendo el espacio para el optimismo crítico.

\section{Conclusión: hacia una psicología organizacional crítica frente al neoliberalismo cultural}

Articular una psicología organizacional en el primer cuarto del siglo XXI, en pleno apogeo de las escuelas de negocios de los grandes centros universitarios, la omnipresencia del cibermundo, la inteligencia artificial, el Big data, la entrada en el Antropoceno, la irrupción de los freelancers y la desigualización radical del mundo, entre otras condiciones disruptivas, implica que tal psicología, en cualquiera de sus encuadres programáticos, se abre al abordaje reflexivo de sí misma y de su campo específico de acción. En este sentido, más que una conclusión de cierre, lo que propongo es abrir un horizonte reflexivo marcado por los desafíos que la viabilicen. Los ejes vertebradores de tal psicología se concuerdan con los siguientes ocho desafíos.

\section{Desafío 1. Giro meta teórico}

La psicología organizacional es posible y necesaria toda vez que haya realizado el giro meta teórico que le obligue a una reflexión teórica sobre sus propias teorías, desde los perfiles formativos de la academia, hasta el campo sensible de la práctica laboral, rechazando lo que, en efecto, atente contra la dignidad humana del trabajador. En el ámbito latinoamericano, por ejemplo, este giro implica trabajar con base en una crítica ética, negativa y ontológica en diálogo con el pensamiento social latinoamericano, y no solo con los supuestos de los Crítical Management Studies europeos (Misoczky, 2017).

\section{Desafío 2. Superación del pensamiento binario}

Se requiere el desplazamiento del pensamiento binario en lo concerniente a la relación subjeto-objeto, dado que, en tanto que estrategia de abordaje de la organización, la psicología organizacional carece de objeto en el sentido estricto del término. Es así porque el objeto no puede ser conocido sin ser modificado, dado que interpretar es ya transformar, y la transformación es siempre la mejor interpretación (Pavon-Cuellar 2018). Así, los pretendidos objetos de la psicología laboral dejan de ser lo que son al ser comprendidos por el psicólogo. Como se dijo al principio, hablar del sujeto de la psicología es referirse a preguntas (problemáticas) que deben ser respondidas, mientras que, referirse a su objeto, es hablar de un producto teórico transitorio e inestable. Parafraseando a Wayne Dyer, se dirá que, cuando se cambia la forma de ver la realidad organizacional, la realidad organizacional cambia de forma.

\section{Desafío 3. Renuncia al gerencialismo}

Es una prioridad que no admite postergación, el desarrollo de una mirada no conformista del gerencialismo como práctica dominante que reduce todos los ámbitos de la vida organizacional a la producción de utilidades. En el caso de la gestión pública, la expansión global del neoliberalismo cultural transformó al gerente clásico de una dependencia estatal en un implementador de recetas enfocadas en la privatización de los derechos públicos, o como señalan Abdala y Puello-Socarrás (2019), en la creación de espacios públicos no estatales. El gerencialismo no es solo la acción consciente del gerente, sino la ideología desde la cual todo se transforma en objeto de gestión. Bajo la égida del gerencialismo, las relaciones sociales, los negocios, los procesos, quedan sometidos a las normativas certificadoras 
de la calidad empresarial. Al abuso de la gestión, reduciéndolas a programas descontextualizados, a normas y políticas que no fueron elaboradas por quienes están obligados a cumplirlas, es a lo que aquí se denomina gerencialismo.

\section{Desafío 4. Confrontar la tendencia de lo neuro}

La psicología organizacional actual amerita una revisión exhaustiva de su tolerancia y complicidad con la "moda de lo neuro" (neuro-liderazgo, neuro-economía, neuro-lingüística, neuro-marketing, neuro-cobranza, neuro-capital humano, neuro-coaching, neuro-ventas, neuro-cultura, etc.), y someter a examen las premisas conceptuales de la psicología positiva y de la inteligencia emocional, en aspectos en los que no pueden dar cuenta de la rigurosidad metodológica seguida para llegar a sus conclusiones. Una actitud científicamente responsable, debe poner límite al optimismo desaforado de la happycracia como "instrumento ideológico enormemente eficaz para justificar consecuencias crueles de la economía de mercado, de excusar sus excesos y maquillar sus locuras" (Cabanas Díaz e Illouz, 2019, citado por Quijano Valencia, 2020).

\section{Desafío 5. Del individuo-líder al líder-azgo}

Si los psicólogos, replicando a los filósofos y a los sociólogos, "se detienen cuando todos pasan de largo", se impone una parada frente al tema del liderazgo y se rompe definitivamente con la dicotomía anacrónica líder-seguidor. Un paso adelante, colocar el énfasis más en los "roles de liderazgo del grupo" y menos en la sacralización del "individuo-líder". Lo que se necesita con urgencia no es un líder fuerte para guiar la organización, sino liderazgo en la organización para dirigirse a sí misma. La evidencia empírica indica que el individuo-líder está sobrevalorado en las organizaciones marcadas por la racionalidad neoliberal, mientras que el líder-azgo, como capacidad de autoorganización, autogestión colectiva y como capital organizacional, permanece subvalorado.

\section{Desafío 6. De la jerarquía a la redarquía}

Junto con la transición que va de la figura del "individuo-líder" al líder-azgo, como capital social e intelectual de una organización para definir su horizonte estratégico, se propone contribuir con la eliminación gradual de la "jerarquía", colocando en su lugar la "redarquía”, un constructo más apropiado a la revolución 4.0, en la que la interacción colaborativa entre colegas será más horizontal y menos vertical. De esta manera se desplazaría el organigrama para valorar mejor al "redigrama", comprendido como un mapa estratégico situado, en el que cada actor dentro de la organización aparece representado por la manera en que se vincula con el resto del equipo, y por su contribución al cumplimiento de los objetivos institucionales, funcionando en redes de compromisos. Desde esta postura, la jerarquía de personas da lugar a la jerarquía de ideas y de responsabilidades.

\section{Desafío 7. El tema de la dignidad}

El psicólogo de la organización habrá de ser un adalid de la dignidad humana, independientemente de la forma que esta adopte en el futuro (teoría del actor-red, cyborg, personas híbridas, post o trans-humanismo, etc.), contribuyendo a la no proliferación de neosujetos producidos a imagen y semejanza del relato neoliberal, devoto del dogma de la productividad.

\section{Desafío 8. Capital al servicio de la vida}

Y finalmente, si la multiplicidad de la vida humana no se reduce a la racionalidad neoliberal (Cingolani y Fjeld, 2019), entonces el capital nunca debería convertirse en el criterio principal del contrato psicológico entre la empresa y el empleado, por más que la realidad socioeconómica así lo demande. En este sentido, los psicólogos organizacionales están llamados a hacer una contra psicología inspirada en los principios del humanismo y no en los de la racionalidad que impone el capital. Vuelve a reivindicarse la idea del espacio organizacional como 
espacio común de realización humana, haciendo una opción preferencial por un contra discurso en el que se coloca al capital al servicio de la vida y no lo opuesto.

\section{Bibliografía}

Abdala,P.R.yPuello-Socarrás,J.F.(2019). Reflexiones sobre la administración pública y el neoliberalismo en nuestra América, Siglo XXI. READ. Revista Eletrônica de Administraçáo (Porto Alegre), 25(2), 22-39. Disponible en https:// dx.doi.org/10.1590/1413-2311.247.94991

Alvarado Peterson, V. (2019). El bienestar en el Estado neoliberal: escenarios de la propiedad en el Gran Santiago. Cultura-hombre-sociedad, 29(2), 13-35. Disponible en https://dx.doi. org/10.7770/0719-2789.2019.cuhso.04.a02

Álvarez Silva, L. A., Estrella Marín, B.M. y Rosas Baldeón, S.M. (2018). Rol del Psicólogo Organizacional en la gestión de Talento Humano. Podium, 33, 79-90. Doi: 10.31095/ podium.2018.33.8

Andrade, V. (2013). Creando subjetividades laborales: implicaciones del discurso psicológico en el mundo del trabajo y las organizaciones. Psicologia \& Sociedade, 25(1), 185-192. Disponible en https://doi.org/10.1590/S0102-718220130 00100020

Armas De Pedraza, T., Venegas Ahumada, C., Salas, G., y Aguilar-Bustamante, M. C. (2019). Neoliberalismo y declive institucional en Chile. La individualización del malestar laboral en psicólogos. Universitas Psychologica, 18(4), 1-17. Disponible en https://doi.org/10.11144/ Javeriana.upsy18-4.ndic

Battista, J. de y Pollo, V. (2017). La violencia del género: libertad de elección y elección forzada en un caso de transexualidad en la infancia. Stylus (Rio de Janeiro), (35), 65-78. Disponible en http://pepsic.bvsalud.org/scielo.php?script=sci_ arttext\&pid=S1676-157X2017000200005\&lng=en\&tlng=es.
Belaustegi, L. (2017). Neoliberalismo como cultura: neosujeto, empresa y Estado desigualitarista. Areas. Revista Internacional de Ciencias Sociales, (36), 25-38. Disponible en https://revistas. um.es/areas/article/view/308031

Bozeman, B. (2015). Causas, efectos y eficacia de la burocratización en las administraciones públicas nacionales: desarrollando reformas sensibles a culturas políticas singulares. Revista del CLAD Reforma y Democracia, (63),5-32. Disponible en https://www.redalyc.org/articulo.oa?id=3575/357542721001

Braunstein, N. A., Pasternac, M. y Frida Saal, G. B. (1982). Psicología: ideología y ciencia. México: Siglo XXI.

Bravo Gil, R., Matute Vallejo, J., y Pina Pérez, J. (2016). Gestión de la identidad corporativa: Evidencias en el sector bancario. Revista de Ciencias Sociales (Ve), XXII(2), 49-62. Disponible en https://www.redalyc.org/articulo.oa? id $=280 / 28049145005$

Cerón-Martínez, A. U. (2020). La construcción del objeto de estudio. Lecciones epistemológicas a partir de la obra de Pierre Bourdieu. Cinta de moebio, (67), 75-84. Disponible en https://dx.doi.org/10.4067/s0717-554x 2020000100075

Cerro del, S. (2013). Psicología de las Organizaciones: retos actuales y futuros. Aloma. 31(2), 9-10.

Chiavenato, I. (2011). Administración de recursos humanos. El capital humano en las organizaciones. México: McGraw Hill.

Chul Han, B. (2019). Psicopolitica. Barcelona: Herder.

Cingolani, P. y Fjeld, A. (2019). La institución de lo común: ¿̨un principio revolucionario para el siglo XXI? Entrevista a Pierre Dardot y Christian Laval. Revista de Estudios Sociales, (70), 65-77. Disponible en https://www.redalyc. org/articulo.oa?id=815/81562397006

Colussi, M. (2018). Influencia del neoliberalismo en las nuevas generaciones. Congreso Centroamericano de Sociología. Enducere, 22,(72). 
Coyne, J.C., y Tennen, H. (2010). Positive psychology in cancer care: bad science, exaggerated claims, and unproven medicine. Annals of Behavioral Medicine, 39, 16-26.

Cruz, F. (1982). Hacia una redefinición del concepto de organización: crítica epistemológica a algunos conceptos que conforman la teoría administrativa en relación con las organizaciones. Cuadernos de Administración Universidad del Valle, 6, 9-63.

Cuervo-Carabel, T. Meneghel, I., Orviz-Martínez, N. y Arce-García, S. (2020). Nuevos retos asociados a la tecnificación laboral: el tecnoestrés y su gestión a través de la Psicología Organizacional Positiva. Revista de Psicologia, Ciències de l'Eduació i de l'Esport, 2020, 38(1).

Dávila, C. (2001). Teorias organizacionales y administración: enfoque crítico. Bogotá: McGraw Hill.

Dittus, R., y Vásquez, C. (2016). Abriendo la autopoiesis: implicancias para el estudio de la comunicación organizacional. Cinta de moebio, (56), 136-146. Disponible en https://dx.doi. org/10.4067/S0717-554X2016000200002

Etzioni, I. (1965). Organizaciones Modernas. México: Uteha,

Giuliano, F. (2018). En torno a lo imposible: una aventura común, entre psicoanálisis y educación, con Jorge Alemán. Estudios de Filosafia Práctica e Historia de las Ideas, (20), 1851-9490.

Graeber, D. (2015). La utopia de las normas. De la tecnología, la estupidez y los secretos placeres de la burocracia. Barcelona: Ariel.

Greco, P. (1972). Epistemología de la psicología, tomo VI de Lógica y conocimiento científico de Jean Piaget. Buenos Aires, Proteo.

Gutiérrez, A. B. (2012. Las prácticas sociales: Una introducción a Pierre Bourdieu. Poliedro.

Harvey, D. (2007). Breve historia del neoliberalismo. Cuestiones de antagonismo. Tres Cantos: Akal.

Hernández Colorado, J. (2017). Fernando Escalante Gonzalbo, Historia mínima del neoliberalismo, México, El Colegio de México, 2015,
320 pp. Estudios Sociológicos, XXXV (103), 203-210. Disponible en https://www.redalyc. org/articulo.oa?id=598/59849770010

Laval, C. y Dardot, P. (2013): La nueva razón del mundo. Ensayo sobre la sociedad neoliberal. Barcelona: Gedisa.

Mandiola, M. (2018). La mirada decolonial en el management. Revista Gestión y Tendencias, 3(1), 6-10. Doi: 10.11565/gesten. v3i1.53

Manrique Solana, R. (2015). La cuestión de la inteligencia emocional. Revista de la Asociación Española de Neuropsiquiatría, 35(128), 801-814. Disponible en https://dx.doi.org/10.4321/ S0211-57352015000400008

Maturana, H. y Varela, F. (1994). De máquinas y seres vivos. Autopoiesis: la organización de lo vivo. Santiago: Editorial Universitaria.

Misoczky, M. C. (2017). ¿De qué hablamos cuando decimos crítica en los estudios organizacionales? Administración \& Desarrollo, 47(1), 141-149.

Morgan, G. (1998). Las imágenes de la organización. México: Alfa-Omega.

Oro Tapia, L. R. (2018). El neoliberalismo como horizonte cultural. La Razón histórica: Revista Hispanoamericana de Historia de las Ideas Politicas y Sociales, (38), 21-38.

Orozco Rincón, E., López Ruiz, E., Zuleta, P., López, D., Giraldo, M. et al. (2013). Rol del psicólogo en las organizaciones. Revista Psicoespacios, 7(11), 409-425. Disponible en http:// revistas.iue.edu.co/index.php/Psicoespacios

Ovejero Bernal, A. (2014). Los perdedores del nuevo capitalismo. Devastación del mundo del trabajo. Madrid: Biblioteca Nueva.

Palomino, T. A. (2015). El trabajador: ¿Recurso humano? Gaceta Laboral, 21(3),335-343. Disponible en https://www.redalyc.org/articulo.oa?id=336/33643814005

Pavón-Cuéllar, D. (2012). Nuestra psicología y su indignante complicidad con el sistema: doce motivos de indignación. Teoría y crítica de la psicología, 2, (202-209). 2116-3480. 
Pavón-Cuéllar, D. (2018). Más allá de la crítica teórica de la psicología: prácticas políticas anticapitalistas en la confluencia del marxismo con el psicoanálisis. Teoría y Crítica de la Psicología, 11(2018), 61-91. Disponible en http://www. teocripsi.com/ojs/.

Peiró, J. (1996). Psicología social de las organizaciones. En Álvaro, J, Garrido, A. \& Torregrosa J. (coord.). Psicología social aplicada. (pp. 155-196). Madrid: Mc Graw Hill.

Peña, M., y Toledo, C. (2017). Ser pobre en el Chile Neoliberal: Estudio discursivo en una escuela vulnerable. Revista Latinoamericana de Ciencias Sociales, Niñez y Juventud, 15(1),207218. Disponible en https://www.redalyc.org/ articulo.oa?id=773/77349627013

Pérez Serrano, G. (2014). Educación, Neoliberalismo y Justicia Social. Martínez Rodríguez, F.M. (2013). Madrid: Ediciones Pirámide, 168 pp. Pedagogía Social. Revista Interuniversitaria, (23),275-278. Disponible en https:// www.redalyc.org/articulo.oa?id $=1350 / 1350$ 29519013.

Pérez-Álvarez, Marino (2012). La psicología positiva: magia simpática. Papeles del Psicólogo, 33(3),183-201. Disponible en: https://www. redalyc.org/articulo.oa?id=778/77824828006

Polo Blanco, J. (2016). Colonialidad del poder y violencia epistémica en América Latina. Revista Latina de Sociología. 6(1). 27-44. Disponible en https://doi.org/10.17979/ relaso.2016.6.1.1967

Porras Velásquez, N. R. (2012). La realidad organizacional: desde la perspectiva psicosocial. Revista Iberoamericana De Psicología, 5(1), 7-18. Disponible en https://doi.org/ 10.33881/2027-1786.rip.5101

Porter, L., Lawler, E., \& Hackman. R. (1975). Behavior in organizations. New York. Mc Graw Hill.

Pulido-Martínez, H. C. y Sato, L. (2013). Y entonces ¿esto de la crítica qué es? De las relaciones entre la psicología y el mundo del trabajo.
Universitas Psychologica, 12(4), 1355- 1368. Doi: 10.11144/Javeriana.UPSY12-4.rpmt

Pulido-Martínez, H. C., y Jaraba Barros, B. (2017). Entre psicologías, prácticas y descentramientos: O de constitución de la subjetividad de los psicólogos. Psicoperspectivas, 16(3), 99-109. Disponible en https://doi.org/10.5027/psicoperspectivas-vol16-issue3-fulltext-1078

Quijano Valencia, O. B. (2020). Cabanas Díaz, Edgar; Illouz, Eva. (2019). Reseña HAPPYCRACIA. Cómo la ciencia y la industria de la felicidad controlan nuestras vidas. Barcelona: Paidós, 224 pp. Innovar, 30(76), 143-145. https://dx.doi.org/10.15446/innovar. v30n76.85219

Rivera Porras, D. A. Carrillo Sierra, S. M., Forgiony Santos, J. O., Nuván Hurtado, I. L. y Rozo Sánchez, A. C. (2018). Cultura organizacional, retos y desafíos para las organizaciones saludables. Revista ESPACIOS. 39(22). Disponible en http://hdl.handle.net/20.500.12442/2165

Rocha Blanco, E. R., Cobo Ortega, A., Vanti, A. A., y Johann, S. (2013). Imágenes organizacionales en empresas brasileñas: detección y análisis con técnicas de minería de datos. Revista de Ciências da Administração, 15(37),105-120. Disponible en https://www.redalyc.org/articulo.oa?id=273 5/273530345009

Rodríguez-Fernández, A. (coord.) (1998). Introducción a la psicología del trabajo y de las organizaciones. Madrid: Pirámide.

Schein, E. (1991). La psicología de la organización. ( $3^{\text {a }}$ ed.). México: Prentice-Hall.

Searle, J. R. (1997). La construcción de la realidad social. Barcelona: Ediciones Paidós Ibérica.

Valverde Brenes, F. J. (2013). Persona o individuo en el (neo) liberalismo: algunos fundamentos ideológicos. Pensamiento Actual, 14(22), 29- 41.

Vera Ruiz, Á., Llanco Gonzales, C. A. y Guevara Rojas, L. A. (2019). Desafiando la formación de psicólogos organizacionales desde una perspectiva de aprendizajes situados en el ámbito micro-empresarial peruano. Cuadernos de Administración, 32(58). 
Psicología organizacional crítica frente a los efectos del neoliberalismo cultural. Una problematización de aspectos prácticos y epistemológicos

Wittke, T. (2005). La empresa: nuevos modos de subjetivación en la organización del trabajo. En L. Schvarstein y L. Leopold (Ed.), Trabajo y subjetividad. Entre lo existente y lo necesario (pp. 147-164). Buenos Aires: Paidós.
Zubillaga, P. (2018). Capitalismo y producción de subjetividad.Sociohistórica, 41, e055. Disponible en https://doi.org/10.24215/18521606e055 